\title{
Determinação do cortisol sérico em terneiras aberdeen angus no desmame precoce e tradicional e seus desempenhos reprodutivos até o primeiro parto
}

\author{
Serum cortisol levels of aberdeen angus calves submitted to early \\ or traditional weaning and their reproductive performance until first calving \\ Marcelo Maronna Dias ${ }^{1}$, Francisco Luiz Rodrigues Lhullier ${ }^{2}$, \\ Fabrício de Azevedo Velho ${ }^{3}$, Ana Paula de Oliveira ${ }^{4} \&$ Paulo Michel Roehe ${ }^{5}$
}

\begin{abstract}
RESUMO
O desmame precoce pode ser uma alternativa para aumentar a eficiência reprodutiva. Cabe investigar possíveis efeitos estressores que desencadeiam respostas neuroendócrinas inespecíficas, liberando glicocorticóides (cortisol). Este estudo visou determinar as taxas fisiológicas do cortisol sérico em terneiras e examinar as possíveis variações que pudessem ocorrer em função do desmame. Um grupo $(\mathrm{n}=24)$ submetido ao desmame com 90 dias pós-parto (precoce) e o outro ( $\mathrm{n}=24)$ com 210 dias (tradicional). Coletou-se soro aos 80 (precoce) e 180 dias (tradicional) para determinar os níveis basais de cortisol antes do desmame. Para avaliar as variações do cortisol sérico pós-desmame, foram feitas coletas 24, 48, 72 e 168 horas pós-desmame sempre pela manhã em função do ritmo circadiano. As determinações do cortisol sérico foram feitas por radioimunoensaio. Os animais foram pesados aos 90, 210, 365 e 730 dias. O desempenho reprodutivo dos animais foi acompanhado pela análise das taxas de prenhez e de perdas de conceptos até o primeiro parto previsto. Os resultados mostraram que os valores de cortisol sérico no grupo

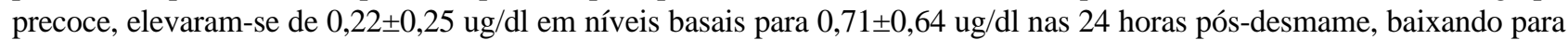

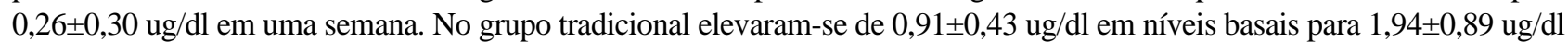

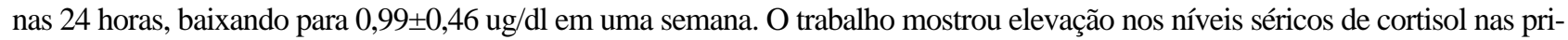
meiras 24 horas pós-desmame, retornando a níveis fisiológicos após uma semana em ambos os grupos; o grupo desmamado tradicionalmente teve um ganho de peso superior $(\mathrm{P}<0,001)$; no desempenho reprodutivo não houve diferenças significativas nas taxas de prenhez e de perdas.
\end{abstract}

Descritores: estresse, cortisol, terneiros, desmame precoce, desmame tradiconal.

\section{ABSTRACT}

The early weaning can be an alternative to enhance reproductive efficiency. Investigating possible stressors related to the practice that can lead to neuroendocrinal responses, releasing glucocorticoids (cortisol) is of great importance. This study aimed to determine physiologic values for serum cortisol in calves and to examine whether different weaning schedules would have any effect on such values. One group $(n=24)$ comprised calves submitted to weaning at 90 days (early weaning); the other group $(n=24)$ comprised calves submitted to weaning at 210 days of age (traditional weaning). Serum samples were colleted before weaning on day 80 (early weaning) and on day 180 (traditional weaning) to determine basal cortisol levels. To evaluate serum cortisol levels after weaning, blood samples were collected at 24, 48, 72 and 168 hours after weaning, always in the mornings, because of cicardian rhythm. Serum cortisol concentration was measured by radioimmunoassay method. Average daily gain at 90 , 210, 365 and 730 days was measures in both groups. Pregnancy rate and losses until parturition were the parameters used to evaluate reproductive performance. Basal serum cortisol $(0,22 \pm 0,25 \mathrm{ug} / \mathrm{dl})$ in the early weaning group enhanced to $0,71 \pm 0,64 \mathrm{ug} / \mathrm{dl}$ in the first 24 hours after weaning, reducing to $0,26 \pm 0,30 \mathrm{ug} / \mathrm{dl}$ after a week. In the traditional weaning group, basal leves $(0,91 \pm 0,43 \mathrm{ug} / \mathrm{dl})$ enhanced to $1,94 \pm 0,89 \mathrm{ug} / \mathrm{dl}$ in the first 24 hours, and reduced to $0,99 \pm 0,46 \mathrm{ug} / \mathrm{dl}$ in a week. This study showed that serum cortisol levels enhanced in the first 24 hours after weaning for both groups, returning to basal levels in a week The traditional weaning group had higher average daily gain $(\mathrm{P}<0,001)$. No significant differences were observed for pregnancy rates and losses until parturition.

Key words: stress, cortisol, early weaning, weaning.

${ }^{1}$ Trabalho originado da Tese de Doutorado do primeiro Autor. Programa de Pós-Graduação em Ciências Veterinárias (PPGCV), Faculdade de Veterinária, Universidade Federal do Rio Grande do Sul (UFRGS), Porto Alegre, RS, Brasil. ${ }^{2}$ Departamento de Farmacologia, Pontifícia Universidade Católica do Rio Grande do Sul. ${ }^{3}$ Médico Veterinário Autônomo. ${ }^{4}$ Mestranda do Programa de Pós Graduação em Microbiologia Agrícola e do Ambiente, UFRGS. ${ }^{5}$ Fundação Estadual de Pesquisa Agropecuária (FEPAGRO) - Centro de Pesquisas Veterinárias Desidério Finamor (CPVDF) e Departamento de Microbiologia do Instituto de Ciências Básicas da Saúde (ICBS) da Universidade Federal do Rio Grande do Sul (UFRGS). CORRESPONDÊNCIA: M.M. Dias [mmaronna@terra.com.br]. 


\section{INTRODUÇÃO}

O aumento da eficiência reprodutiva em rebanhos de cria tem sido a meta de técnicos e pecuaristas. O desmame precoce pode ser uma alternativa [5]. Esta ferramenta sob o ponto de vista prático, pode gerar melhores taxas de prenhez imediatas [4].

Precoce, é o desmame entre dois e três meses de idade, intermediário, aquele realizado entre quatro e cinco meses, e tradicional, o desmame realizado com seis meses ou mais [21]. O desmame precoce pode afetar a conversão alimentar, pela abrupta separação da mãe entre dois e três meses, ao redor de $70 \mathrm{~kg}$ [12].

A recria das novilhas assume um importante papel nos sistemas de criação, sendo pertinente desenvolver um modelo economicamente sustentável de recria [19]. Foi demonstrado que as novilhas para chegarem aos dois anos com $300 \mathrm{~kg}$ em um primeiro acasalamento, necessitam ganharem diariamente pesos diferentes, ou seja, precisam aumentar 250 gramas por dia quando desmamadas com $150 \mathrm{~kg}$ de peso, 220 gramas por dia com $170 \mathrm{~kg}$ e 190 gramas por dia com $190 \mathrm{~kg}$ [1]. Sobre o ritmo de ganho de peso pós-desmame, ficou demonstrado que terneiros desmamados precocemente têm um ganho de peso menor que os terneiros desmamados tradicionalmente [8].

Vários autores associam o estresse do desmame precoce ao atraso no crescimento, pela separação da mãe [12,17,20], ou a outros efeitos, que contribuem para futuras perdas produtivas nos terneiros $[11,13,14$, $16,22]$.

É pertinente investigar os efeitos de estressores visto que, desencadeam respostas neuroendócrinas inespecíficas em terneiros, na tentativa de restaurar o equilíbrio homeostático, liberando glicocorticóides [6,7, $9,15]$. O cortisol plasmático pode ser usado como indicador de estresse em bovinos [17].

\section{MATERIAIS E MÉTODOS}

\section{Animais}

Foram selecionadas 48 terneiras Aberdeen Angus nascidas nos meses de setembro e outubro de 2002. A metade delas foi desmamada com 90 dias e a outra metade permaneceu junto às mães até atingir 210 dias de idade. A seleção dos animais ocorreu, procurando-se estabelecer dois lotes o mais homogêneo possível. Foram feitas pesagens dos animais aos 90, 210, 365 e 730 dias de idade, sempre com um turno de jejum. O peso determinado para ocorrer o primeiro serviço com inseminação artificial foi de $300 \mathrm{~kg}$.

\section{Coletas de sangue}

As coletas de sangue para a determinação do cortisol foram efetuadas às 24, 48, 72 e 168 horas pós-desmame. Para saber-se os níveis de cortisol nas terneiras antes do desmame, coletou-se sangue aos 80 e 180 dias de idade para cada grupo. As coletas foram realizadas sempre no turno da manhã, para evitar possíveis variações hormonais em função do ritmo circadiano apresentado por hormônios como o cortisol. O sangue foi coletado da veia jugular. Todos os animais passaram por uma inspeção clínica antes das coletas.

\section{Análise do cortisol}

Após a coleta o sangue era colocado em isopor com gelo ficando em repouso durante 60 minutos para retração do coágulo. Posteriormente era transportado para o Departamento de Bioquímica do Instituto de Ciências Básicas da Saúde da Universidade Federal do Rio Grande do Sul e obtinha-se o soro por centrifugação. Os soros foram armazenadas em freezer a $-70^{\circ} \mathrm{C}$. A determinação do cortisol foi feita por radioimunoensaio através de um kit comercial (In Vitro ICN Biomedicals, Inc. Costa Mesa, Califórnia).

\section{Análise estatística}

Os dados foram analisados com o auxílio do programa SPSS, versão 12.0. Os dados descritivos foram apresentados com médias e desvios padrões para as variáveis contínuas (níveis de cortisol-basal, 24h, $48 \mathrm{~h}, 72 \mathrm{~h}$ e $168 \mathrm{~h}$ após desmame, idade) e com frequiências absolutas e relativas para variáveis categóricas (sexo, grupos de desmame - precoce e tradicional). Para as análises comparativas, foi usado o teste $\mathrm{t}$ de Student e U de Mann-Whitney, conforme fossem assumidos pressupostos de simetria ou assimetria. Foi utilizado nível de significância $\alpha=0,05$.

\section{RESULTADOS}

No grupo do desmame precoce, observa-se na Tabela 1 que, a elevação nos níveis de cortisol sérico ocorrida na coleta das 24 horas após o desmame foi estatisticamente significativa em relação a todas as coletas, com exceção da coleta das 48 horas em que não houve diferença significativa. Isto evidencia que o valor encontrado para às 24 horas pós-desmame não se deve ao efeito do manejo, pois foi significativamente maior que o valor basal, que são das próprias terneiras submetidas ao mesmo tipo de manejo. Os 
Tabela 1. Níveis de cortisol sérico (médias e desvio padrão), em terneiras desmamadas precoce e tradicionalmente.

\begin{tabular}{|c|c|c|c|c|c|}
\hline Grupo & Coleta & Idade (dias) & Média* & $\mathrm{DP}^{*}$ & $\mathbf{P}^{*}$ \\
\hline \multirow{4}{*}{ Desmame Precoce } & Basal (0) & 80 & 0,22 & 0,25 & $\begin{array}{c}1-0,003 \\
2-0,13 \\
3-0,97 \\
4-0,86\end{array}$ \\
\hline & 24h após desmame (1) & 90 & 0,71 & 0,64 & $\begin{array}{c}0-0,003 \\
2-0,09 \\
3-<0,001 \\
4-0,001\end{array}$ \\
\hline & 48h após desmame (2) & 90 & 0,46 & 0,53 & $\begin{array}{l}0-0,13 \\
1-0,09 \\
3-0,07 \\
4-0,08\end{array}$ \\
\hline & 72h após desmame (3) & 90 & 0,20 & 0,19 & $\begin{array}{c}0-0,97 \\
1-<0,001 \\
2-0,07 \\
4-0,87 \\
\end{array}$ \\
\hline \multirow{6}{*}{ Desmame Tradicional } & 168h após desmame (4) & 90 & 0,26 & 0,30 & $\begin{array}{c}0-0,86 \\
1-0,001 \\
2-0,08 \\
3-0,87\end{array}$ \\
\hline & Basal (0) & 180 & 0,91 & 0,43 & $\begin{array}{c}1-0,003 \\
2-0,52 \\
3-0,82 \\
4-0,92\end{array}$ \\
\hline & 24h após desmame (1) & 210 & 1,94 & 0,89 & $\begin{array}{c}0-0,003 \\
2-0,13 \\
3-0,03 \\
4-0,007\end{array}$ \\
\hline & 48h após desmame (2) & 210 & 1,28 & 1,02 & $\begin{array}{l}0-0,52 \\
1-0,13 \\
3-0,68 \\
4-0,60\end{array}$ \\
\hline & 72h após desmame (3) & 210 & 0,84 & 0,60 & $\begin{array}{c}0-0,82 \\
1-0,003 \\
2-0,68 \\
4-0,99\end{array}$ \\
\hline & 168h após desmame (4) & 210 & 0,99 & 0,46 & $\begin{array}{c}0-0,92 \\
1-0,007 \\
2-0,60 \\
3-0,99\end{array}$ \\
\hline
\end{tabular}

valores médios dos níveis séricos de cortisol e seus desvios padrões podem ser vistos na Tabela $1 . \mathrm{Na}$ Figura 1, pode-se visualizar que ocorreu uma elevação em relação aos níveis considerados basais nas 24 horas, e que a curva tendeu à normalização com o passar de uma semana.

No grupo tradicionalmente desmamado, a Tabela 1 mostra que, a elevação nos níveis de cortisol sérico ocorrida na coleta das 24 horas após o desmame foi estatisticamente significativa em relação a todas as coletas, com exceção da coleta das 48 horas em que não houve diferença significativa. Conforme já foi observado nos animais submetidos ao desmame precoce, pode-se observar, neste grupo também, na Figura 1, que houve uma elevação nos níveis séricos de cortisol nas 24 horas pós-desmame, normalizandose após uma semana.

Quanto aos pesos, a Tabela 2 mostra que os animais do desmame tradicional apresentaram ganho de peso estatisticamente significativo em relação ao 

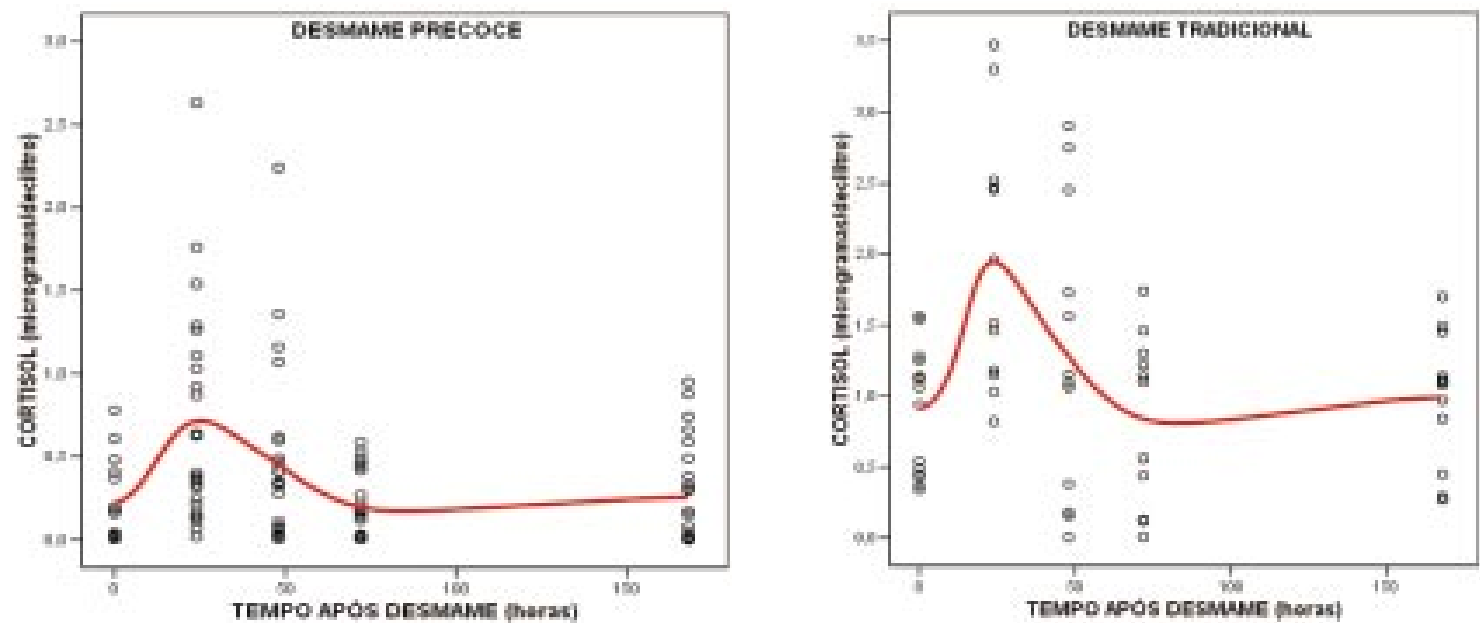

Figura 1. Variação dos níveis séricos de cortisol em terneiras desmamadas aos 90 dias de idade (desmame precoce) e 210 dias (desmame tradicional). As coletas de sangue foram realizadas antes do desmame ( 0 , basal) e às 24 h, 48 h, 72 h e 168 horas (uma semana) após o desmame.

Tabela 2. Pesagens de fêmeas desde o desmame até os dois anos, aos 90, 210, 365 e 730 dias, nos grupos desmamados precoce e tradicionalmente.

\begin{tabular}{cccc}
\hline Idade & $\begin{array}{c}\text { Peso } \\
\text { Grupo Desmame } \\
\text { Precoce* }^{*}\end{array}$ & $\begin{array}{c}\text { Peso } \\
\text { Grupo Desmame } \\
\text { Tradicional* }\end{array}$ & P \\
\hline 90 dias $(\mathrm{kg})$ & $101 \pm 8,46$ & $105 \pm 9,62$ & 0,13 \\
210 dias $(\mathrm{kg})$ & $156 \pm 8,74$ & $183 \pm 17,41$ & $<0,001$ \\
365 dias $(\mathrm{kg})$ & $175 \pm 9,00$ & $200 \pm 21,44$ & $<0,001$ \\
730 dias $(\mathrm{kg})$ & $306 \pm 9,25$ & $323 \pm 16,11$ & $<0,001$ \\
\hline${ }^{*}$ Dados apresentados com média \pm desvio padrão. &
\end{tabular}

animais do outro grupo, com exceção das terneiras com 90 dias entre as quais não houve diferença significativa. Apesar das diferenças de peso, as novilhas entraram em serviço com o peso preconizado de $300 \mathrm{~kg}$.

A Tabela 3 mostra uma performance reprodutiva muito semelhante entre os dois grupos de desmame, pois não houve diferença estatisticamente significativa entre suas taxas de prenhez e ocorreu apenas um aborto e um natimorto em cada grupo, tanto que nos dois grupos não houve diferença significativa no índice de desmame.

\section{DISCUSSÃO}

Na discussão sobre os grupos submetidos às duas formas diferentes de desmame, é importante considerar dois aspectos: as variações dos níveis de cortisol dentro do mesmo grupo e entre os dois grupos de desmame. No mesmo grupo, ocorreu uma eleva-
Tabela 3. Dados comparativos de desempenho de terneiras desmamadas aos 90 dias de idade (grupo precoce) e aos 210 dias de idade (grupo tradicional) desde o desmame até o primeiro parto previsto.

\begin{tabular}{|c|c|c|}
\hline Parâmetros & Grupo Precoce & Grupo Tradicional \\
\hline Animais desmamados & 24 & 24 \\
\hline Mortalidade 1 ano & 1 & 0 \\
\hline$\%$ Mortalidade & 4,17 & 0 \\
\hline $\mathrm{n}=$ número de indivíduos & 23 & 24 \\
\hline Idade ao desmame (dias) & 90 & 210 \\
\hline Mês do desmame & Dezembro/2002 & Abril/2003 \\
\hline Idade primeiro serviço & 2 anos & 2 anos \\
\hline Em serviço - nov. 2004 & 23 & 24 \\
\hline Prenhas & 19 & 21 \\
\hline$\%$ Prenhez & 82,61 & 87,50 \\
\hline Aborto & 1 & 0 \\
\hline$\%$ Aborto & 5,26 & 0 \\
\hline Natimorto & 0 & 1 \\
\hline$\%$ Natimorto & 0 & 4,76 \\
\hline Perda por distocia terneiros & 0 & 1 \\
\hline$\%$ Perda distocia terneiros & 0 & 4,76 \\
\hline Perda por distocia vacas & 0 & 1 \\
\hline$\%$ Perda distocia vacas & 0 & 4,17 \\
\hline Vacas com cria & 18 & 19 \\
\hline $\begin{array}{l}\% \text { de vacas com cria } \\
\text { com uma semana }\end{array}$ & 78,26 & 79,17 \\
\hline Mortalidade terneiros 1 mês & 1 & 0 \\
\hline Mortalidade terneiros 2 mês & 0 & 1 \\
\hline Numero terneiros mamando & 17 & 18 \\
\hline $\begin{array}{l}\text { Índice de desmame } \\
\text { em dez. } 2005 \%\end{array}$ & 73,91 & 75 \\
\hline
\end{tabular}


ção significativa nas 24 horas pós-desmame, que pode ser atribuída a um eventual estresse, mesmo que passageiro. Isto foi encontrado por [18] que detectaram variações significativas nas 24 horas pós-desmame em terneiros cruza angus-hereford. Entre os grupos, houve variações significativas entre as cinco determinações de cortisol $(\mathrm{P}<0,05)$, as quais podem estar relacionadas com as diferenças de idade, partindo-se do princípio de que no início do experimento os níveis basais eram diferentes [8]. A elevação dos níveis séricos ou plasmáticos de cortisol com a idade, inclusive ao longo do envelhecimento, tem sido constatada [2,10]. A elevação destes níveis com a idade é atribuída a uma progressiva perda da eficiência nos mecanismos de regulação por "feedback" [3].

Quanto ao ganho de peso, as novilhas que foram desmamadas precocemente atingiram o objetivo de entrar em serviço com $300 \mathrm{~kg}$. Isto assemelha-se como encontrado por [1] que indicam que os ganhos de peso compensatórios de primavera ajudam no desenvolvimento da novilha.

Quanto a performance reprodutiva os dois grupos mostraram-se muito semelhante no desempenho, evidenciando que o desmame precoce não interferiu na reprodução.

\section{CONCLUSÃO}

A determinação dos valores séricos de cortisol mostra-se útil como método para avaliar níveis de estresse em bovinos, pois neste trabalho, indica que, em situações de desmame, há possibilidade da ocorrência de estresse em curto período de tempo após o desmame. $\mathrm{O}$ desmame precoce não compromete o crescimento e o desempenho reprodutivo das terneiras a ele submetidas, em comparação com as terneiras desmamadas pelo método tradicional.

Agradecimentos. Ao CNPq, à FEPAGRO (CPVDF) e UFRGS pelo apoio na realização da pesquisa.

\section{REFERENCIAS}

1 Barcellos J.O.J., Costa E.C., Silva M.D., Semmelmann C. E. N., Montanholi Y.R., Prates E. R., Grecellé R., Mendes R., Wunsch C. \& Rosa J.R.P. 2003. Crescimento de Fêmeas Bovinas de Corte Aplicado aos Sistemas de Cria. Publicação Ocasional. $n^{\circ} 1$. Porto Alegre: UFRGS, 72p.

2 Bauer M.E. 2005. Stress, glucocorticoids and ageing of the immune system. Stress. 8 (1): 69-83.

3 Bjorntorp P. 2002. Alterations in the ageing corticotropic stress-response axis. Novartis Found Symposium, 242: 46-58.

4 Borges J. B. 2002. Alternativas para indução da atividade cíclica ovariana em vacas de corte no pós-parto. 115f. Porto Alegre, RS. Tese de Doutorado - Programa de Pós-graduação em Ciências Veterinárias, Universidade Federal do Rio Grande do Sul.

5 Cachapuz J.M.S. 1997. Experiências com Desmame aos 90 e 60 dias. $2^{\circ}$ ed. Porto Alegre: EMATER/RS, 52p.

6 Coppo J.A. 2000. Impacto del destete precoz sobre el medio interno de terneros cruza cebu. $216 \mathrm{f}$. Corrientes, Tesis de Doctorado - Facultad Ciências Veterinárias, Universidad Nacional del Nordeste del Argentina.

7 Coppo J.A. 2001. Estrés o alarma simpática? Actualización bioquímico-clínica. Selecciones Veterinárias, 9 (4): 336-342.

8 Coppo J.A., Mussart N.B., Revidatti M.A. \& Capellari A. 2003. Absence of biochemically demonstrable stress in early weaned half-bred zebu calves. Ciência e Investigación Agraria, 30: 97-105.

9 Duncan J.R. \& Prasse K.W. 1986. Veterinary Laboratory Medicine. Clinical Pathology. 2nd ed Ames, IOWA: University Press, $243 \mathrm{p}$.

10 Fontani G., Lodi L., Felice A., Corradeschi F. \& Lupo C. 2004. Attentional, emotional and hormonal data in subjects of different ages. European Journal of Applied Physiology. 92: 452-461.

11 Fraser A.F. \& Broom D.M. 1990. Farm animal behavior and welfare. $3^{\text {rd }}$ ed. London: Balliere Tidall, 448 p.

12 Galli I.O., Monge A.R. \& Hofer C.C. 1995. Destete precoz: clave para nuevos sistemas de producción de carne vacuna en la provincia de Corrientes. Ed INTA Concepción del Uruguay. Curso-Taller. 7-25.

13 Grimes J. F. \& Turner T.B. 1991. Early weaning of fall-born beef calves. 1. Preweaning calf and cow performance. Journal of Production Agriculture. 4: 464-468.

14 Harvey R.W. \& Burns J.C. 1988. Creep grazing and early weaning effects on cow and calf productivity. Journal of Animal Science. 66: 1109-1114.

15 Kaneko J.J., Harvey J.W. \& Bruss M.L. 1997. Clinical biochemistry of domestic animals. 5th ed. New York: Academic Press. $932 \mathrm{p}$.

16 Kubisch H.M. \& Makarechian M. 1987. Effects of date of weaning on post-weaning performance of three breed groups. Canadian Journal of Animal Science. 67: 941-946. 
17 Lefcourt A. M. 1986. Usage of the stress as it applies to cattle. Flemish Veterinary Journal. 55: 258.

18 Lefcourt A.M. \& Elsasser T.H. 1995. Adrenal responses of Angus x Hereford cattle to the stress of weaning. Journal of Animal Science. 73: 2669-2676.

19 Owens F.N., Dubeski P. \& Hanson C.F. 1993. Factors that alther the growth and development of ruminants. Journal of Animal Science. 71: 3138-3150.

20 Renner J.E. 1989. Los Terneros. Primera Edicion. Buenos Aires: Hemisferio Sur, 66p.

21 Rovira J. 1996. Manejo nutritivo de los rodeos de cria em pastoreo. Montevidéo: Hemisferio Sur, 287p.

22 Yousef M.K. 1985. Stress physiology in livestock - basic principles. Boca Raton: CRC Press, v.2, 217p. 